\title{
PENGARUH KEMANDIRIAN BELAJAR TERHADAP HASIL BELAJAR MATEMATIKA SISWA SMPN 1 BOJONEGARA PADA MATERI ALJABAR
}

\author{
Atika Indah Safitri ${ }^{1}$, Heni Pujiastuti ${ }^{2}$ \\ ${ }^{1}$ Program Studi Pendidikan Matematika, Universitas Sultan Ageng Tirtayasa \\ atikaindahsafitri@gmail.com \\ ${ }^{2}$ Program Studi Pendidikan Matematika, Universitas Sultan Ageng Tirtayasa \\ henipujiastuti@untirta.ac.id
}

\begin{abstract}
ABSTRAK
Penelitian ini bertujuan untuk mengetshui ada tidaknya pengauh antara kemandirian belajar terhadap hasil belajar matematika siswa SMPN 1 Bojonegara pada Materi Aljabar. Penelitian ini merupakan penelitian ex post facto, dengan populasi seluruh siswa SMPN 1 Bojonegara dan untuk sampel diambil kelas VII C dan VII D yang seluruhya berjumlah 75 orang. Pengumpulan data dilakukan dengan menggunakan angket untuk kemandirian belajar dan tes untuk hasil belajar. Hasil penelitian ini diperoleh dengan pengolahan data yang dilakukan menggunakan SPSS versi 26 untuk pengujian normalitas data kemandirian belajar, hasil belajar dan residu serta untuk pengujian liniertitas dan signifikansi regresi. Hasil penelitian menunjukan bahwa terdapa pengaruh yang signifikan antara kemandirian belajar terhadap hasil belajar dengan pengaruh sebesar $96,03 \%$.
\end{abstract}

Kata Kunci : Aljabar, Hasil Belajar Matematika, Kemandirian Belajar.

\begin{abstract}
This study aims to recognize whether there is any influence between learning independence and mathematics learning outcomes of students of SMPN 1 Bojonegara on Algebra Material. This research is an ex post facto study, with a population of all students of SMPN 1 Bojonegara and for the sample taken classes VII C and VII D, totaling 75 people. Data collection is done by using a questionnaire for learning independence and tests for learning outcomes. The results of this study were obtained by processing data using SPSS version 26 to test the normality of learning independence data, learning outcomes and residues as well as to test linearity and significance of regression. The results showed that there was a significant influence between learning independence on learning outcomes with an influence of 96.03\%.
\end{abstract}

Keywords: Algebra, Mathematics Learning Outcomes, Learning Independence.

\section{PENDAHULUAN}

Matematika merupakan pelajaran yang penting untuk dipelajari oleh siswa di sekolah maupun oleh mahasiswa di perguruan tinggi. Matematika juga merupakan mata pelajaran yang berdaya guna tinggi. Hal ini karena matematika tidak terlepas dari perannya dalam perkembangan Ilmu Pengetahuan dan
Teknolgi (IPTEK). Mengingat pentingnya matematika dalam IPTEK dan kehidupan sehari-hari pada umunya, maka matematika perlu dipahami dan dikuasai oeh semua lapisan masyarakat terutama sekolah (Marina,2018).

Matematika memiliki banyak materi yang perlu dipelajari, salah satunya adalah aljabar. Semua orang pasti pernah 
menggunakan konsep aljabar dalam permasalahan sehari-hari, baik yang disadari maupun tidak disadari khususnya bagi mereka yang pernah menempuh jenjang pendidikan, tapi kenyataan di lapangan menunjukkan hasil yang memprihatinkan dalam pembelajaran aljabar (Hasibuan, 2015). Aljabar bukan merupakan materi yang mudah jika siswa hanya bergantung pada penjelasan guru tanpa mempelajari lagi dirumah. Banyak siswa yang meminta guru untuk mengulangi penjelasannya dalam setiap proses pembelajaran aljabar dan masih banyak siswa sering melakukan kesalahan dalam mengerjakan persoalan yang terkait dengan aljabar. Pemahaman siswa mengenai materi aljabar sangat tergantung pada pembelajaran di kelas bersama guru. Kegiatan pembelajaran akan berlangsung dengan baik apabila ada komunikasi timbal-balik antara guru dan siswa (Marina, 2018). Oleh karena itu, siswa dituntut untuk bersikap aktif, kreatif, dan inovatif dalam menanggapi setiap pelajaran yang diajarkan, sehingga pesan yang disampaikan dalam bentuk materi dapat diterima siswa. Sikap aktif, kreatif dan inovatif terwujud dengan menempatkan siswa sebagai subyek pendidikan, sedangkan peran guru adalah fasilitator dan bukan sebagai sumber utama belajar.

Pelaksanaan kegiatan di kelas, dirancang agar siswa dapat memperoleh hasil belajar yang memuaskan. Salah indikator keberhasilan dari pendidikan adalah hasil belajar siswa (Sartika,2019). Hasil belajar merupakan pencapaian yang diperoleh siswa selama mengikuti pembelajaran, sehingga untuk menentukan pembelajaran yang dilakukan berhasil atau tidak dapat dilakukan dengan melihat bagaimana hasil belajar siswa. Hasil belajar siswa tentu tidak selalu mendapat hasil yang baik, cukup sering siswa yang mendapat nilai yang kurang baik dan hal ini tentunya perlu dilakukan perbaikan agar hasil belajar siswa sesuai dengan yang diharapkan sehingga tujuan belajar dapat tercapai.

Baik dan buruknya hasil belajar tentu dipengaruhi oleh beberapa faktor yang dapat mempengaruhi hasil belajar. Faktor- faktor tersebut dapat berasal dari dalam diri siswa maupun dari luar diri siswa. Faktor yang berasal dari luar diri siswa dapat berupa kondisi lingkungan belajar, model pembelajaran, metode pembelajaran, kemampuan guru, dan lain sebagainya (Leonard dan Supardi, 2010). Faktor yang berasal dari dalam diri siswa yaitu motivasi belajar siswa, minat belajar siswa, kemandirian belajar dan lain sebagainya.

Berdasarkan pernyataan Bloom mengenai hasil belajar, terdapat tiga ranah hasil belajar, yaitu kognitif, afektif, dan psikomotorik. Ranah kognitif berisi perilaku yang menekankan aspek intelektual seperti pengetahuan, dan keterampilan berfikir (Wahyuni, 2019). Hasil belajar dalam penyataan Bloom dibagi menjadi beberapa tipe yaitu: (1) Pengetahuan (knowledge), (2) Pemahaman (comprehention), (3) Penerapan (application), (4) Analisis (analysis), dan (5) Evaluasi (evaluation). Sedangkan Menurut Kwarthwohl, Bloom dan Maisa (1973) ranah afektif diklasifikasikan menjadi 5 tingkatan yaitu: (1) penerimaan, (2) partisipasi, (3) penilaian, (4) organisasi dan (5) pembentukan pola hidup. Oleh karena itu, Hasil belajar siswa dapat dilihat dari pencapaian siswa dalam bertambahnya pengetahuannya, keterampilannya atau perubahan sikap pada diri seorang siswa.

Salah satu faktor yang mempengaruhi hasil belajar yaitu kemandirian belajar siswa. Guru dalam menjelaskan materi tentunya memiliki banyak hambatan dalam proses pembelajaran. Rencana Pelaksanaan Pembelajaran (RPP) terkadang tidak sesuai dengan pelaksanaan karena adanya waktu libur atau kegiatan lain yang membuat penyampaian materi tidak maksimal. Kemandirian belajar siswa diperlukan untuk kondisi seperti ini. Siswa perlu belajar dengan mandiri untuk lebih memahami materi matematika karena sumber belajar tidak hanya dari guru (Suhendi, 2011).

Siswa yang memiliki kemandirian belajar yang baik akan memudahkan dalam pembelajaran matematika. Karena kemandirian belajar akan membuat siswa aktif belajar sebelum dan sesudah proses pembelajaran selesai (Egok, 2015). Siswa 
yang mempersiapkan diri untuk belajar sebelum pembelajaran dikelas dan setelah pembelajaran selesai tentu akan mempengaruhi hasil belajar.

Berdasarkan penjabaran diatas, penelitian ini bertujuan untuk mendeskripsikan bagaimana pengaruh antara kemandirian belajar dengan hasil belajar matematika pada materi bangun ruang sisi datar.

\section{METODE PENELITIAN}

Penelitian ini bertujuan untuk mengetahui adanya hubungan antara kemandirian belajar dan hasil belajar siswa, dimana penelitian ini akan menerangkan hubungan sebab akibat dari kedua variabel dan menguji hipotesis pada penelitian ini. berdasarkan tujuan penelitiannya, maka penelitian ini merupakan penelitian penelitian ex post facto yang bersifat kausalitas.

Populasi dari penelitian ini adalah seluruh siswa SMPN 1 Bojonegara tahun ajaran 2019/2020 dan untuk sampel penelitiannya yaitu siswa kelas VII C dan
VII D, dimana kelas VII C terdapat 34 siswa dan kelas VII D terdapat 36 siswa, sehingga jumlah sampel yang diambil adalah 75 siswa.

Populasi dari penelitian ini adalah seluruh siswa SMPN 1 Bojonegara tahun ajaran 2019/2020 dan untuk sampel penelitiannya yaitu siswa kelas VII C dan VII D, dimana kelas VII C terdapat 34 siswa dan kelas VII D terdapat 36 siswa, sehingga jumlah sampel yang diambil adalah 75 siswa.

Teknik pengumpulan data yang dilakukan meliputi tes hasil belajar dan kemandirian belajar. Untuk menjawab hipotesis penelitian. Selanjutnya juga akan ditentukan persamaan regresi yang berguna untuk memprediksi nilai variabel dependen menggunakan variabel independen dengan syarat data harus dalam bentuk interval. Proses analisis data dilakukan dapat menggunakan bantuan SPSS 26.

Secara lengkap alur pelaksanaan penelitian ini dapat dilihat pada gambar berikut.

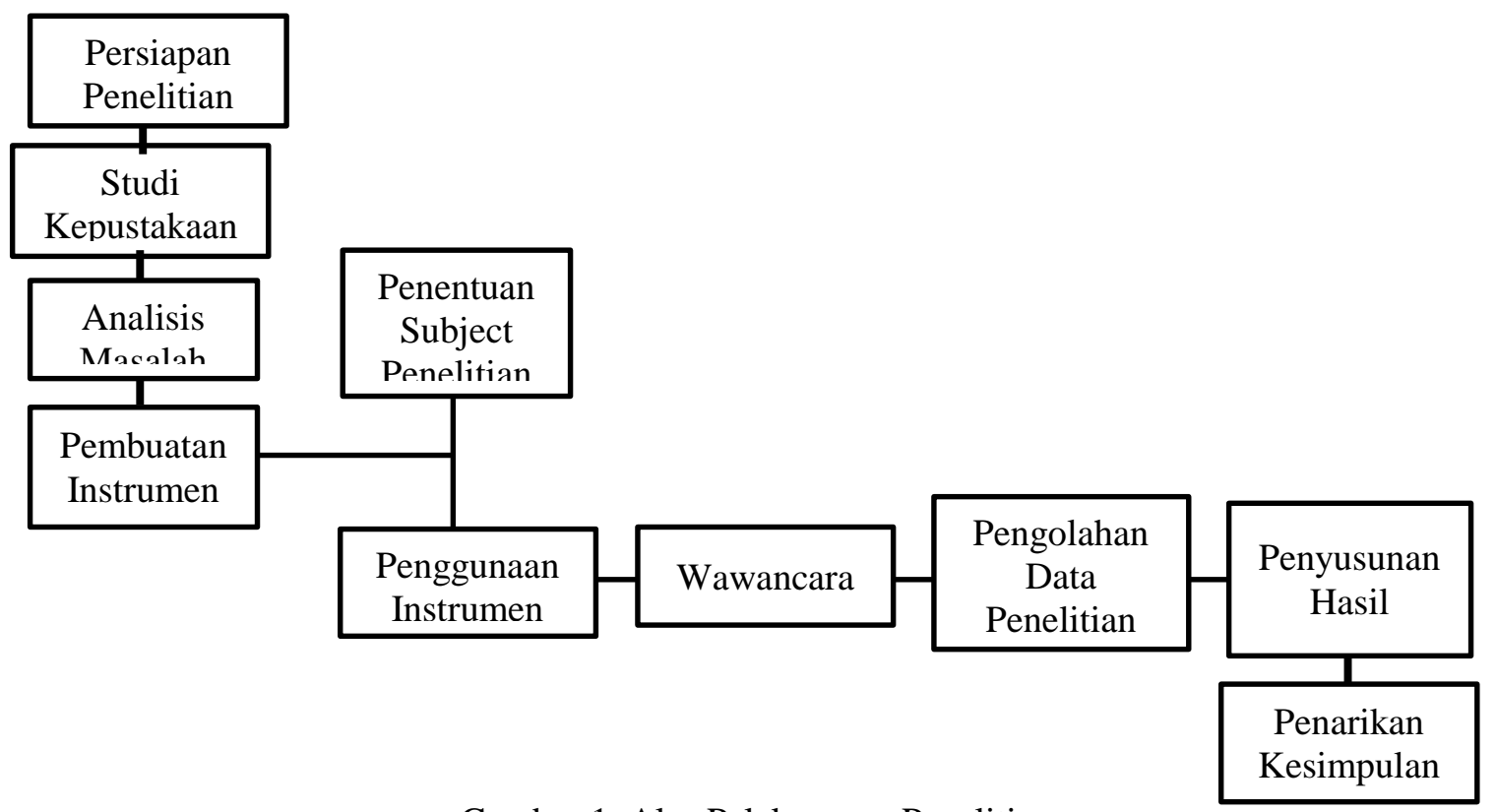

Gambar 1. Alur Pelaksanaan Penelitian

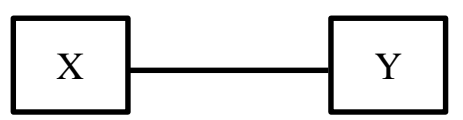

Gambar 2. Model Struktural Hubungan Antar Variabel

Keterangan:

$\mathrm{X}=$ Kemandirian Belajar

$\mathrm{Y}=$ Hasil Belajar 
HASIL DAN PEMBAHASAN

1. Uji Normalitas Variabel $X$

Tabel 1. Hasil Uji Normalitas Variabel X

One-Sample Kolmogorov-Smirnov Test

\begin{tabular}{|c|c|c|}
\hline & & $\mathrm{X}$ \\
\hline $\mathrm{N}$ & & 75 \\
\hline Normal & Mean & 40,99 \\
\hline Parameters ${ }^{\mathrm{a}, \mathrm{b}}$ & $\begin{array}{l}\text { Std. } \\
\text { Deviation }\end{array}$ & 16,160 \\
\hline Most Extreme & Absolute & ,151 \\
\hline Differences & Positive & ,151 \\
\hline & Negative &,- 077 \\
\hline Test Statistic & &, 151 \\
\hline Asymp. Sig. (2 & led) &, $000^{\mathrm{c}}$ \\
\hline
\end{tabular}

Berdasarkan uji normalitas yang dilakukan pada data kemandirian belajar siswa, diperoleh hasil uji statistiknya sebesaar 0,151 yang berarti data tersebut normal. Hal ini karena hasil tersebut lebih besar dari 0,05 .

\section{Uji Normalitas Variabel Y}

Tabel 2. Hasil Uji Normalitas Variabel Y

One-Sample Kolmogorov-Smirnov Test

\begin{tabular}{llr}
\hline & & $\mathrm{Y}$ \\
\hline $\mathrm{N}$ & & 75 \\
\hline Normal & Mean & 44,51 \\
Parameters $^{\mathrm{a}, \mathrm{b}}$ & $\mathrm{Std}$. & 17,083 \\
& Deviation & \\
\hline Most Extreme & Absolute &, 152 \\
\cline { 2 - 3 } Differences & Positive &, 152 \\
& Negative &,- 076 \\
\hline Test Statistic & &, 152 \\
\hline Asymp. Sig. (2-tailed) &, $000^{\mathrm{c}}$ \\
\hline
\end{tabular}

Berdasarkan uji normalitas yang dilakukan pada data hasil belajar matematika, diperoleh hasil uji statistiknya sebesaar 0,152 karena hasil tersebut lebih besar dari 0,05 . Hal ini berarti data tersebut normal. 


\section{Persamaan Regresi}

Tabel 3. Persamaan Regresi

\begin{tabular}{|c|c|c|c|c|c|c|}
\hline \multicolumn{7}{|c|}{ Coefficients $^{\mathrm{a}}$} \\
\hline & \multirow[t]{2}{*}{ Model } & \multicolumn{2}{|c|}{$\begin{array}{l}\text { Unstandardized } \\
\text { Coefficients }\end{array}$} & $\begin{array}{l}\text { Standardized } \\
\text { Coefficients }\end{array}$ & \multirow[b]{2}{*}{$\mathrm{t}$} & \multirow[b]{2}{*}{ Sig. } \\
\hline & & $\mathrm{B}$ & Std. Error & Beta & & \\
\hline \multirow{2}{*}{1} & (Constant) & 2,049 & 1,085 & & 1,888 & ,063 \\
\hline & $X$ & 1,036 &, 025 & ,980 & 42,008 & ,000 \\
\hline
\end{tabular}

Tabel 4. Nilai $\mathrm{R}^{2}$

\begin{tabular}{lcccc}
\hline \multicolumn{6}{c}{ Model Summary } \\
\hline Model & $\mathrm{R}$ & R Square & $\begin{array}{c}\text { Adjusted R } \\
\text { Square }\end{array}$ & $\begin{array}{c}\text { Std. Error of } \\
\text { the Estimate }\end{array}$ \\
\hline 1 & $980^{\mathrm{a}}$ &, 960 &, 960 & 3,428 \\
\hline \multicolumn{2}{l}{ a. Predictors: (Constant), X } & & \\
\hline
\end{tabular}

Perhitungan untuk mencari persamaan regresi didapat nilai a adalah 2,0491 dan nilai b adalah 1,0359. Maka persamaan regresinya adalah $\mathrm{Y}=$ 2,0491+1,0359x dengan $\mathrm{R}^{2}$ sebesar 0,960. Karena a sebesar 2,0491 sementara b adalah
1,0359. Artinya, apabila faktor lain dianggap tetap, kenaikan $\mathrm{X}$ sebesar 1 satuan, maka $\mathrm{Y}$ mengalami kenaikan 2,0491. Berdasarkan hasil perhitungan ini maka terdapat pengaruh antara variabel $\mathrm{X}$ terhadap

$\mathrm{Y}$.

\section{Uji Normalitas Residu}

Tabel 5. Hasil Uji Normalitas Residu

\begin{tabular}{llr}
\hline \multicolumn{3}{c}{ One-Sample Kolmogorov-Smirnov Test } \\
\hline $\mathrm{N}$ & \multicolumn{1}{c}{ Residu } \\
\hline Normal Parameters $^{\mathrm{a}, \mathrm{b}}$ & Mean & 75 \\
& Std. Deviation & 3,404749 \\
\hline Most Extreme & Absolute &, 084 \\
Differences & Positive &, 084 \\
& Negative &,- 073 \\
\hline Test Statistic & &, 084 \\
\hline Asymp. Sig. (2-tailed) & &, $200^{\mathrm{c}, \mathrm{d}}$ \\
\hline
\end{tabular}

Berdasarkan uji normalitas yang dilakukan pada data hasil belajar matematika, diperoleh hasil uji statistiknya sebesaar 0,084 karena hasil tersebut lebih besar dari 0,05 maka dapat disimpulkan bahwa data tersebut normal. 
Tabel 6. Hasil Uji Linieritas

\begin{tabular}{|c|c|c|c|c|c|c|c|}
\hline \multicolumn{8}{|c|}{ ANOVA Table } \\
\hline & & & \multicolumn{2}{|l|}{ Sum of } & \multicolumn{2}{|l|}{ Mean } & \multirow[b]{2}{*}{ Sig. } \\
\hline & & & Squares & Df & Square & $\mathrm{F}$ & \\
\hline \multirow[t]{7}{*}{$\mathrm{Y} * \mathrm{X}$} & Between & (Combined) & 21224,749 & 41 & 517,677 & 46,171 & ,000 \\
\hline & Groups & Linearity & 20736,915 & 1 & 20736,915 & 1849,52 &, 000 \\
\hline & & & & & & 1 & \\
\hline & & Deviation from & 487,834 & 40 & 12,196 & 1,088 & , 405 \\
\hline & & Linearity & & & & & \\
\hline & \multicolumn{2}{|c|}{ Within Groups } & 369,998 & 33 & 11,212 & & \\
\hline & \multicolumn{2}{|l|}{ Total } & 21594,747 & 74 & & & \\
\hline
\end{tabular}

Didapatkan bahwa nilai fhitung tuna cocok $=1,088$. Dan $\mathrm{f}$ tabel $=1,7557$ dengan taraf sig 5\%, karena Fhitung < Ftabel maka
Ho diterima dan H1 ditolak, sehingga regresi $\mathrm{Y}$ atas $\mathrm{X}$ adalah linier.

\section{Analisis Regresi}

Tabel 7. Hasil Uji Analisis Regresi

\begin{tabular}{|c|c|c|c|c|c|c|}
\hline \multicolumn{7}{|c|}{ ANOVA $^{\mathbf{a}}$} \\
\hline Model & & Sum of Squares & Df & Mean Square & $\mathrm{F}$ & Sig. \\
\hline \multirow[t]{3}{*}{1} & Regression & 20736,915 & 1 & 20736,915 & 1764,676 &, $000^{\mathrm{b}}$ \\
\hline & Residual & 857,831 & 73 & 11,751 & & \\
\hline & Total & 21594,747 & 74 & & & \\
\hline
\end{tabular}

Nilai Fhitung $=1764,676$. Dan Ftabel adalah 3,9720 dengan taraf signifikan 5\%. Berdasarkan hasil tersebut maka Fhitung < Ftabel sehingga Ho ditolak dan H1 diterima. Dengan demikian terdapat pengaruh yang siginifikan antara variabel $\mathrm{X}$ dan variabel $Y$.

Pengujijan normalitas yang dilakukan pada data kemandirian belajar siswa, hasil belajar siswa dan residu yang dilakukan dengan SPSS versi 26. Didapat hasil pengujian yaitu data kemandirian belajar sebesar 0,151, hasil belajar sebesar 0,152 dan residu sebesar 0,084. Ketiga hasil tersebut, baik hasil pengujian normalitas data kemandirian belajar, hasil belajar dan residu lebih besar dari 0,05 sehingga dapat diartikan jika ketiga data tersebit normal. Persamaan linear yang didapat dengan mencari nilai a dan nilai dengan SPSS didapatkan nilai a sebesar 2,0491 dan nilai b sebesar 1,0359, sehingga persamaan regresinya adalah $\mathrm{Y}=2,0491+1,0359 \mathrm{x}$ dengan $\mathrm{R}^{2}$ sebesar 0,960 . Karena a sebesar 2,0491 sementara $b$ adalah 1,0359. Artinya, apabila faktor lain dianggap tetap, kenaikan $\mathrm{X}$ sebesar 1 satuan, maka $\mathrm{Y}$ mengalami kenaikan 2,0491. Berdasarkan hasil perhitungan ini maka terdapat pengaruh antara variabel $\mathrm{X}$ terhadap $\mathrm{Y}$, yang artinya terdapat pengaruh antara kemandirian belajar terhadap hasil belajar siswa. Pengujian lain untuk memperkuat hipotesis dilakukan dengan melakukan uji linearitas dan analisis regresi. Pada pengujian linearitas dan regresi didapat Fhitung untuk linearitas sebesar 1,008 dan untuk pengujian signifikansi regresi yaitu 1764,676, sedangkan untuk Ftabel dengan taraf signifan 5\% diperoleh 1,7557 untuk uji linieritas dan 3,9720 untuk uji signifikansi regresi. Oleh karena itu 
menyebabkan $\mathrm{H}_{\mathrm{O}}$ ditolak dan $\mathrm{H}_{1}$ diterima, sehingga dapat disimpulkan bahwa terdapat pengaruh antara kemandirian belajar terhadap hasil belajar dengan pengaruh sebesar 96,03\%.

Menurut The Liang Gie(1988) salah satu cara belajar yang baik adalah disiplin dan keteraturan dalam belajar, dalam hal ini meliputi mengulang bahan pelajaran, membaca dan membuat catatan, konsentrasi, mengerjakan tugas, cara mengatur waktu belajar dapat mempengaruhi hasil belajar siswa (Wahyuni, 2019). Hal tersebut mengarah pada kemandirian belajar siswa, sehingga benar bahwa kemandirian belajar siswa dapat mempengaruhi hasil belajar siswa.

\section{KESIMPULAN DAN SARAN}

Berdasarkan hasil pengujian data yang telah dilakukan, didapat hasil pengujian normalitas data kemandirian belajar sebesar 0,151, hasil belajar sebesar 0,152 dan residu sebesar 0,084 . Ketiga hasil tersebut, baik hasil pengujian normalitas data kemandirian belajar, hasil belajar dan residu lebih besar dari 0,05 sehingga dapat diartikan jika ketiga data tersebit normal. Pengujian linieritas dan siginikansi regresi yang dilakukan didapat Fhitung untuk pengujian linearitas yaitu 1,008 dan untuk pengujian signifikansi regresi yaitu 1764,676, sedangkan untuk Ftabel dengan taraf signifan 5\% diperoleh 1,7557 untuk uji linieritas dan 3,9720 untuk uji signifikansi regresi. Oleh karena itu menyebabkan $\mathrm{H}_{\mathrm{O}}$ ditolak dan $\mathrm{H}_{1}$ diterima, sehingga dapat disimpulkan bahwa terdapat pengaruh antara kemandirian belajar terhadap hasil belajar dengan pengaruh sebesar 96,03\%.

Hasil belajar matematika dapat menghasilkan hasil yang baik jika terdapat kerja sama antara guru dan siswa. Matematika merupakan pelajaran yang tidak mudah sehingga membutuhkan waktu yang cukup untuk memahaminya. Pembelajaran dikelas kurang jika digunakan untuk memahami sepenuhnya sehingga perlu kemandirian belajar siswa agar dapat memahami materi matematika. Menurut The Liang Gie(1988) salah satu cara belajar yang baik adalah disiplin dan keteraturan dalam belajar, sehingga guru sebaiknya memberi arahan kepada siswanya agar belajar secara mandiri sebelum dan sesudah pembelajaran di kelas untuk memperoleh hasil belajar yang baik.

\section{DAFTAR PUSTAKA}

Egok, A. S. (2016). Kemampuan Berpikir Kritis dan Kemandirian Belajar dengan Hasil Belajar Matematika. Jurnal Pendidikan Dasar, 7.

Firmansyah, D. (2015). Pengaruh Strategi Pembelajaran dan Minat Belajar Terhadap Hasil Belajar Matematika. Jurnal Pendidikan Unsika, 3, 34-44.

Hajerina. (2017). Penerapan Pendekatan Contexual Teaching and Learning (CTL) untuk Meningkatkan Hasil Belajar Siswa SMPN 18 Sigi pada Materi Sistem Persamaan Linear Dua Variabel(SPLDV). Al-Khwarizmi, 5(2), 113-122.

Hasibuan, I. (2015). Hasil Belajar Siswa pada Materi Aljabar di Kelas VII SMP Negeri 1 Banda Aceh Tahun Pelajaran 2013/2014. Jurnal Peluang, 4, 5-11.

Marina, \& Suciati, I. (2019). Pengaruh Pendekatan Kontekstual Terhadap Prestasi Belajar Matematika Aritmatika Sosial Siswa Kelas VII SMP Negeri 3 Kota Palu. Jurnal Guru Tua, 1(1).

Ningsih, R. (2016). Pengaruh Kemandirian Belajar dan Perhatian Orang Tua Terhadap Prestasi Belajar Matematika. Jurnal Formatif, 6(1), 73-84.

Rachmayani, D. W. I. (2014). Penerapan Pembelajaran Reciprocal Teaching untuk Meningkatkan Kemampuan Komunikasi Matematis dan Kemandirian Belajar Matematika Siswa. Jurnal Pendidikan Unsika, 2(November), 13-23.

Suhendri, H. (n.d.). Pengaruh Metode Pembelajaran Problem Solving Terhadap Hasil Belajar Matematika Ditinjau dari Kemandirian Belajar. Jurnal Formatif, 3(2), 105-114.

Suhendri, H. (2014). Pengaruh Kecerdasan Matematis-Logis dan Kemandirian 
Belajar Terhadap Hasil Belajar Matematika. Jurnal Formatif, 1(1), 29-39.

Supardi U.S., S. U. S. (2015). Pengaruh Adversity Qoutient terhadap Prestasi Belajar Matematika. Formatif: Jurnal Ilmiah Pendidikan MIPA, 3(1), 61-71. https://doi.org/10.30998/formatif.v3i1. 112

Wahyuni, D. S. (2019). Pengaruh Cara Belajar Terhadap Hasil Belajar Matematika SMK Janur Persada Sigi. Jurnal Guru Tua, 2(1), 53-59 